\title{
High frequency of $Y$ chromosome microdeletions in male infertility patients with 45,X/46,XY mosaicism
}

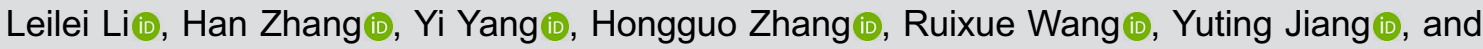 \\ Ruizhi Liu (ib
}

Center for Reproductive Medicine and Center for Prenatal Diagnosis, The First Hospital of Jilin University, Changchun, Jilin, China

\begin{abstract}
The mosaic 45,X/46,XY karyotype is a common sex chromosomal abnormality in infertile men. Males with this mosaic karyotype can benefit from assisted reproductive therapies, but the transmitted abnormalities contain $45, X$ aneuploidy as well as $Y$ chromosome microdeletions. The aim of this study was to investigate the clinical and genetic characteristics of infertile men diagnosed with 45,X/46,XY mosaicism in China. Of the 734 infertile men found to carry chromosomal abnormalities, 14 patients were carriers of $45, X / 46, X Y$ mosaicism or its variants, giving a prevalence of $0.27 \%(14 / 5269)$ and accounting for $1.91 \%$ $(14 / 734)$ of patients with a chromosomal abnormality. There were ten cases $(71.43 \%, 10 / 14)$ of $45, X$ mosaicism exhibiting AZF microdeletions. Case 1 and Case 4 had AZFc deletions, and the other eight cases had AZFb $+c$ deletions. A high frequency of $Y$ chromosome microdeletions were detected in male patients with 45,X/46,XY mosaicism. Preimplantation genetic diagnosis should be offered to men having intracytoplasmic sperm injection for hypospermatogenesis caused by $45, X / 46, X Y$ mosaicism, to avoid the risk of transfering AZF microdeletions in addition to X monosomy in male offspring.
\end{abstract}

Key words: 45,X/46,XY mosaicism; Y chromosome microdeletions; Male infertility; Azoospermia; Oligozoospermia

\section{Introduction}

The three main genetic factors known to cause male infertility are cystic fibrosis gene mutations that cause obstructive azoospermia, and chromosomal abnormalities and $Y$ chromosome microdeletions that cause spermatogenic impairment (1). Infertile patients with severe spermatogenic impairment have an increased proportion of genetic abnormalities. The mosaic 45,X/46,XY karyotype is a common sex chromosomal abnormality associated with male infertility.

The detection rate of $45, \mathrm{X} / 46, \mathrm{XY}$ mosaicism, which is a rare chromosomal abnormality and usually not diagnosed in time, is $1.5 / 10,000$ newborns (2). The clinical phenotype of $45, X / 46, X Y$ individuals is very broad and includes Turner females, varying degrees of genital malformations, and men with normal phenotypes (3). The gonads of such patients have been reported as streak gonads, ovarian-like, and/or exhibiting other histopathological abnormalities in previous case reports, small studies, and large multicenter histological studies $(4,5)$.

The 45,X/46,XY mosaic patients are usually infertile and can be identified by karyotype detection. Recently, a close relationship between $Y$ chromosome microdeletions and $45, X / 46, X Y$ mosaicism has been identified in Turner's syndrome patients, patients with mixed gonadal dysgenesis
(MGD), and males with infertility. Research also suggested that $\mathrm{Y}$ chromosome instability due to $\mathrm{Y}$ chromosome microdeletions is more notable in gonadal cells (6-8).

Males with the mosaic $45, X / 46, X Y$ karyotype can benefit from assisted reproductive therapies, but prenatal diagnosis plays an important role in preventing the potential transmission of genetic abnormalities. Such transmitted abnormalities contain the $45, X$ aneuploidy as well as $Y$ chromosome microdeletions. The aim of our study was to investigate the clinical and genetic characteristics of infertile individuals diagnosed with 45,X/46,XY mosaicism in China.

\section{Material and Methods}

\section{Patients}

Five thousand two hundred and sixty-nine cases of primary infertility in men aged 22-46 years were collected from July 7, 2008 to April 21, 2018 at the Center for Reproductive Medicine of the First Hospital of Jilin University. The duration of infertility in these patients ranged from 1 to 11 years. The clinical examination results and family history, gestation history, adverse environmental exposure history, and lifestyle habits of these patients were collected for etiological analysis. The exclusion criteria were

Correspondence: Ruizhi Liu: <Irz410@126.com>

Received July 7, 2019 | Accepted October 10, 2019 
infertility caused by female factors, anatomical factors, infectious factors, immune factors, and other known infertility factors. The inclusion criterion was men with infertility considered to be caused by genetic factors other than the exclusion factors. The study protocol was approved by the Ethics Committee of the First Hospital of Jilin University, and written informed consent was obtained from all participants.

\section{Cytogenetic analysis}

All patients were screened by cytogenetic analysis. Peripheral blood $(0.5 \mathrm{~mL})$ was collected in sterile tubes containing $30 \mathrm{U} / \mathrm{mL}$ heparin. Lymphocytes were cultured in appropriate culture media (Yishengjun; Guangzhou Baidi Biotech, China) for $72 \mathrm{~h}$, and then treated with $20 \mu \mathrm{g} /$ $\mathrm{mL}$ colcemid for $1 \mathrm{~h}$. G-banding of metaphase chromosomes and karyotype analysis were performed using our previously published methods (9).

\section{Detection of AZF microdeletions}

AZF microdeletions were detected by multiplex polymerase chain reaction (PCR). Ten specific sequencetagged sites, including SY84 and SY86 for AZFa, SY127, SY134, and SY143 for AZFb, and SY152, SY157, SY254, and SY255 for AZFc, were collected according to the European Academy of Andrology and European Molecular Genetics Quality Network. Sex-determining region $Y$ (SRY) and human zinc-finger protein-encoding genes (ZFX/ZFY) located on the $X$ and $Y$ chromosomes were selected as internal control primers (10). Two milliliters of peripheral blood was extracted from each patient with EDTA anticoagulant and then genomic DNA was separated using a blood DNA extraction mini kit (Beijing Tiangen Biotech Co., Ltd., China).

Multiplex PCR amplification was performed using an Amplitron II PCR apparatus (Barnstead/Thermolyne, USA) and $10 \mu \mathrm{L}$ reaction solutions containing $200 \mathrm{ng}$ of genomic DNA, $1.5 \mathrm{mmol} / \mathrm{L} \mathrm{Mg}^{2+}, 800 \mu \mathrm{mol} / \mathrm{L}$ deoxyribonucleotide triphosphates, $10 \mathrm{pmol} / \mathrm{L}$ of each primer, and $2 \mathrm{U}$ Taq polymerase. Thermocycling (Veriti Thermal Cycler 96-well, Alpha-SE, Applied Biosystems, USA) consisted of denaturation for 6 min at $94^{\circ} \mathrm{C}$, followed by 35 cycles of $94^{\circ} \mathrm{C}$ for $40 \mathrm{~s}, 55^{\circ} \mathrm{C}$ for $45 \mathrm{~s}$, and $72^{\circ} \mathrm{C}$ for $60 \mathrm{~s}$, with a final extension at $72^{\circ} \mathrm{C}$ for $6 \mathrm{~min}$. After completion of cycling, the PCR product was removed and mixed with $2 \mu \mathrm{L}$ of $6 \times$ buffer solution, then loaded onto a $1.5 \%$ agarose gel containing $0.5 \mu \mathrm{g} / \mathrm{mL}$ ethidium bromide. Electrolysis was performed at $80 \mathrm{~V}$ for $35 \mathrm{~min}$, and results were observed using an ultraviolet transmissometer. Samples with detected AZF microdeletions were repeated to verify the results. Samples from a fertile man and woman were used as positive and negative controls, respectively, and water was used as a blank control.

\section{Results}

A total of 734 carriers with chromosomal abnormalities were detected in 5,269 male patients with primary infertility. Of 734 carriers of chromosomal abnormalities, 14 patients were carriers of a $45, \mathrm{X} / 46, \mathrm{XY}$ mosaicism or its variants, as shown in Supplementary Table S1, giving a prevalence of $0.27 \%(14 / 5269)$ in patients with male infertility and accounting for $1.91 \%$ (14/734) of patients with chromosomal abnormalities. Of these 14 patients with mosaicism, 42.86\% (6/14) were mosaic for a structurally abnormal $Y$ chromosome in the $46, X Y$ cell line. Eight of the 14 patients $(57.14 \%)$ had pure $45, X$ and $46, X Y$ mosaicism. One $(1 / 14,7.14 \%)$ of these patients exhibited oligozoospermia, while the remaining 13 patients exhibited azoospermia. The results of karyotype and AZF microdeletion analysis for the 14 patients are summarized in Supplementary Table S1.

We screened the 14 cases for $Y$ chromosome microdeletions by PCR using $10 \mathrm{Y}$ chromosome-specific markers. Ten cases $(71.43 \%, 10 / 14)$ of the $45, X$ mosaicism exhibited AZF microdeletions. Case 1 and Case 4 represented $A Z F C$ deletions, and the other eight cases had $\mathrm{AZFb}+\mathrm{C}$ deletions. Cases 5 and 6 exhibited $a$ structurally abnormal $Y$ chromosome with no microdeletions detected in the AZF region. The remaining two cases with no AZF deletion had a mosaic of $45, \mathrm{X}$ of 19 and $60 \%$.

\section{Discussion}

The prevalence of $45, X / 46, X Y$ mosaicism or its variants in this male infertility study was $0.27 \%(14 /$ 5269), which is much higher than its incidence in newborns. This mosaicism was an important genetic factor for spermatogenesis failure. An important finding of this study was the identification of the very high frequency $(71.43 \%)$ of $Y$ chromosome microdeletions in patients with sex chromosome mosaicism $(45, \mathrm{X} / 46, \mathrm{XY})$. $\mathrm{Y}$ chromosome microdeletions are one of the main causes of male infertility. It occurs in about 1 in 4000 men in the general population, but its frequency is significantly higher in infertile men. According to global estimates, about $10 \%$ of cases of idiopathic infertility occur due to deletions in the $A Z F$ region. The detection rate of $A Z F$ microdeletion in $45, X / 46, X Y$ patients can relate to the clinical phenotype, with different detection rates for the differing phenotypes, but it is basically maintained in a stable range. One previous study found an AZF deletion frequency of approximately $40 \%$ in $45, \mathrm{X} / 46, \mathrm{XY}$ mosaicism patients who presented with partial and mixed gonadal dysgenesis (6), whereas Patsalis et al. reported a deletion incidence rate of $50 \%$ in four male patients with azoospermia or mixed gonadal dysgenesis (7). In three other reports, 10 patients with male infertility showed a $100 \%$ frequency of $Y$ chromosome deletions $(8,11,12)$. The prevalence of AZF deletions in patients with $45, X / 46, X Y$ mosaicism was lower in our study compared with other reports of the same clinical phenotypes, and this may reflect the larger sample size in our study (Table 1, refs. 6-8, 11-16). 
Table 1. Frequency of AZF microdeletions in men with 45,X/46,XY mosaicism or its variants reported in the literature.

\begin{tabular}{|c|c|c|c|}
\hline Reference & Number of patients & Clinical features & $\begin{array}{l}\text { Frequency of AZF microdeletions } \\
\text { on peripheral blood lymphocytes }\end{array}$ \\
\hline Siffroi et al., 2000 (8) & 6 & Azoospermia & $100 \%(6 / 6)$ \\
\hline Patsalis et al., 2002 (14) & 12 & $\begin{array}{c}\text { Sexual ambiguities or characteristic of } \\
\text { Turner syndrome }\end{array}$ & $33 \%(4 / 12)$ \\
\hline Papadimas et al., 2001 (13) & 1 & Ambiguous genitalia & $100 \%(1 / 1)$ \\
\hline Alvarez-Nava et al., 2008 (15) & 11 & Gonadal dysgenesis & $27 \%(3 / 11)$ \\
\hline Cui et al., 2007 (11) & 1 & Azoospermia & $100 \%(1 / 1)$ \\
\hline dos Santos et al., 2013 (6) & 15 & Partial and mixed gonadal dysgenesis & $40 \%(6 / 15)$ \\
\hline Alvarez-Nava et al., 2006 (16) & 2 & $\begin{array}{c}\text { Pure gonadal dysgenesis and Turner } \\
\text { syndrome phenotype or mixed gonadal } \\
\text { dysgenesis }\end{array}$ & $0(0 / 2)$ \\
\hline Bettio et al., 2006 (12) & 3 & Infertility & $100 \%(3 / 3)$ \\
\hline Patsalis et al., 2005 (7) & 4 & Azoospermia or mixed gonadal dysgenesis & $50 \%(2 / 4)$ \\
\hline Current study & 14 & Azoospermia or oligozoospermia & $71.43 \%(10 / 14)$ \\
\hline
\end{tabular}

We noted that the $45, \mathrm{X} / 46, \mathrm{XY}$ mosaic patients with AZF microdeletion may have a vertical inheritance of the $Y$ chromosome carrying AZF deletions from their father. This possibility was supported by a report that described a 17year-old boy with ambiguous genitalia who had a 45, X/46, $X Y$ mosaic karyotype and AZF microdeletions (13). These findings suggested that fathers who carry AZF microdeletions would transfer a defective $Y$ chromosome to male offspring through natural or assisted reproductive technologies, which may also greatly increase the risk of offspring containing sex chromosome aneuploidy. This risk is currently difficult to assess because it includes not only $45, X / 46, X Y$ individuals in this study, but also those with $\mathrm{X}$ monosomy.

The structural aberrations of the $Y$ chromosome on the karyotype is often associated with the $Y$ chromosome aneuploidy. A previous report showed that more than half of the patients with $Y$ chromosome structural abnormalities may present with $45, X$ mosaic cell lines (8). In the present study, $42.86 \%(6 / 14)$ of the mosaic patients were mosaic for a structurally abnormal $Y$ chromosome in 46, $X Y$ cell lines; three with Yqh-, one with a Yq deletion, one

\section{References}

1. Kim ED, Bischoff FZ, Lipshultz LI, Lamb DJ. Genetic concerns for the subfertile male in the era of ICSI. Prenat Diagn 1998; 18: 1349-1365, doi: 10.1002/(SICI)1097-0223 (199812)18:13<1349::AID-PD504 > 3.0.CO;2-\#.

2. Rosa RF, D'Ecclesiis WF, Dibbi RP, Rosa RC, Trevisan P, Graziadio $C$, et al. 45, $\mathrm{X} / 46, \mathrm{XY}$ mosaicism: report on 14 patients from a Brazilian hospital. A retrospective study. Sao Paulo Med J 2014; 132: 332-338, doi: 10.1590/1516-3180. 2014.1326729. with a $\mathrm{Yp}+$, and the last with a dicentric $\mathrm{Y}$. Four of these patients also presented with AZF microdeletions.

In conclusion, we found a high frequency of $Y$ chromosome microdeletions in male patients with $45, \mathrm{X} /$ $46, X Y$ mosaicism. The percentage of the detected $45, X$ cell population was not related to the severity of the symptoms. To quantify the potential risk, we recommend that preimplantation diagnosis should be offered when men have intracytoplasmic sperm injection for hypospermatogenesis caused by $45, \mathrm{X} / 46, \mathrm{XY}$ mosaicism, to avoid the transfer of AZF microdeletions in addition to $45, X$ in male offspring.

\section{Supplementary material}

Click here to view [pdf].

\section{Acknowledgment}

This work was supported by the Science and Technology Department of Jilin Province (20160101048JC).

3. Lindhardt Johansen M, Hagen CP, Rajpert-De Meyts E, Kjaergaard S, Petersen BL, Skakkebaek NE, et al. 45,X/46, $X Y$ mosaicism: phenotypic characteristics, growth, and reproductive function--a retrospective longitudinal study. J Clin Endocrinol Metab 2012; 97: E1540-E1549, doi: 10. 1210/jc.2012-1388.

4. Tosson H, Rose SR, Gartner LA. Description of children with 45,X/46,XY karyotype. Eur J Pediatr 2012; 171: 521-529, doi: 10.1007/s00431-011-1600-9. 
5. Cools M, Pleskacova J, Stoop H, Hoebeke P, Van Laecke E, Drop SL, et al. Gonadal pathology and tumor risk in relation to clinical characteristics in patients with $45, \mathrm{X} / 46, \mathrm{XY}$ mosaicism. J Clin Endocrinol Metab 2011; 96: E1171-80, doi: 10.1210/jc.2011-0232.

6. dos Santos AP, Andrade JG, Piveta CS, de Paulo J, Guerra G $\mathrm{Jr}$, de Mello MP, et al. Screening of $Y$ chromosome microdeletions in 46,XY partial gonadal dysgenesis and in patients with a 45,X/46,XY karyotype or its variants. BMC Med Genet 2013; 14: 115, doi: 10.1186/1471-2350-14-115.

7. Patsalis PC, Skordis N, Sismani C, Kousoulidou L, Koumbaris $\mathrm{G}$, Eftychi $\mathrm{C}$, et al. Identification of high frequency of $\mathrm{Y}$ chromosome deletions in patients with sex chromosome mosaicism and correlation with the clinical phenotype and Y-chromosome instability. Am J Med Genet A 2005; 135 : 145-149, doi: 10.1002/ajmg.a.30712.

8. Siffroi JP, Le Bourhis C, Krausz C, Barbaux S, Quintana-Murci $\mathrm{L}$, Kanafani S, et al. Sex chromosome mosaicism in males carrying $Y$ chromosome long arm deletions. Hum Reprod 2000; 15: 2559-2562, doi: 10.1093/humrep/15.12.2559.

9. Zhang HG, Liu XY, Hou Y, Chen S, Deng S, Liu RZ. Reproductive outcome of a case with familial balanced translocation $\mathrm{t}(3 ; 6)$ : implications for genetic counseling. Genet Mol Res 2015; 14: 2809-2815, doi: 10.4238/2015. March.31.11.

10. Dada R, Gupta NP, Kucheria K. Molecular screening for Yq microdeletion in men with idiopathic oligozoospermia and azoospermia. J Biosci 2003; 28: 163-168, doi: 10.1007/ BF02706215.

11. Cui YX, Xia XY, Pan LJ, Wang YH, Hao LJ, Yao B, et al. Gonosomal mosaicism from deleted $Y$ chromosomal nondisjunction. J Androl 2007; 28: 377-380, doi: 10.2164/ jandrol.106.001834.

12. Bettio D, Venci A, Rizzi N, Negri L, Setti PL. Clinical and molecular cytogenetic studies in three infertile patients with mosaic rearranged $Y$ chromosomes. Hum Reprod 2006; 21: 972-975, doi: 10.1093/humrep/dei426.

13. Papadimas J, Goulis DG, Giannouli C, Papanicolaou A, Tarlatzis B, Bontis JN. Ambiguous genitalia, 45,X/46,XY mosaic karyotype, and $Y$ chromosome microdeletions in a 17-year-old man. Fertil Steril 2001; 76: 1261-1263, doi: 10.1016/S0015-0282(01)02877-1.

14. Patsalis PC, Sismani C, Quintana-Murci L, Taleb-Bekkouche F, Krausz C, McElreavey K. Effects of transmission of $\mathrm{Y}$ chromosome AZFc deletions. Lancet 2002; 360: 1222-1224, doi: 10.1016/S0140-6736(02)11248-7.

15. Alvarez-Nava F, Puerta $H$, Soto M, Pineda L, Temponi A. High incidence of $Y$-chromosome microdeletions in gonadal tissues from patients with 45,X/46,XY gonadal dysgenesis. Fertil Steril 2008; 89: 458-460, doi: 10.1016/j.fertnstert. 2007.02.058.

16. Alvarez-Nava F, Puerta H. Y-chromosome microdeletions in 45,X/46,XY patients. Am J Med Genet $A$ 2006; 140: 1128-1130, doi: 10.1002/ajmg.a.31231. 